\title{
Effect of Ruboxistaurin on Blood-Retinal Barrier Permeability in Relation to Severity of Leakage in Diabetic Macular Edema
}

\section{Citation}

Strøm, Charlotte, Birgit Sander, Kristian Klemp, Lloyd Paul Aiello, Henrik Lund-Andersen, and Michael Larsen. 2005. Effect of Ruboxistaurin on Blood-Retinal Barrier Permeability in Relation to Severity of Leakage in Diabetic Macular Edema. Invest. Ophthalmol. Vis. Sci. 46, no. 10: 3855. doi:10.1167/iovs.05-0096.

\section{Published Version}

doi:10.1167/iovs.05-0096

\section{Permanent link}

http://nrs.harvard.edu/urn-3:HUL.InstRepos:33776266

\section{Terms of Use}

This article was downloaded from Harvard University's DASH repository, and is made available under the terms and conditions applicable to Other Posted Material, as set forth at http:// nrs.harvard.edu/urn-3:HUL.InstRepos:dash.current.terms-of-use\#LAA

\section{Share Your Story}

The Harvard community has made this article openly available.

Please share how this access benefits you. Submit a story.

Accessibility 


\title{
Effect of Ruboxistaurin on Blood-Retinal Barrier Permeability in Relation to Severity of Leakage in Diabetic Macular Edema
}

\author{
Charlotte Strøm, ${ }^{1}$ Birgit Sander, ${ }^{1}$ Kristian Klemp, ${ }^{1}$ Lloyd Paul Aiello, ${ }^{2,3}$ \\ Henrik Lund-Andersen, ${ }^{1}$ and Michael Larsen ${ }^{1}$
}

Purpose. The purpose of the study was to investigate the effect of orally administered ruboxistaurin (RBX, LY333531), a selective protein kinase $C \beta$ inhibitor, on the permeability of the blood-retinal barrier in patients with diabetic macular edema.

Methods. Forty-one patients with diabetic macular edema were randomly assigned to an 18-month randomized, placebo-controlled, double-masked trial including four study arms $(4,16$, or $32 \mathrm{mg} / \mathrm{d} \mathrm{RBX}$, or placebo). The RBX group comprised 30 patients ( 42 eyes) and the placebo group 11 patients ( 13 eyes). Retinal vascular leakage was assessed using vitreous fluorometry at baseline and after 3, 12, and 18 months. Statistical analysis of the effect of treatment accounted for repeated measurements and tested potential interaction with baseline permeability, $\mathrm{HbA}_{1 \mathrm{c}}$, and arterial blood pressure.

Results. Statistical analysis and modeling demonstrated a significant interaction between RBX treatment at any dosage and baseline permeability ( $P=0.032$, mixed models). A threefold or higher increase in retinal vascular leakage at baseline was associated with a significant reduction $(30 \%)$ in retinal vascular leakage after RBX treatment compared with placebo. Visual acuity was normal at baseline and remained unchanged throughout the study.

ConcLusions. RBX treatment was associated with a reduction of retinal vascular leakage in eyes that had diabetic macular edema and markedly elevated leakage at baseline. These data suggest that clinical benefit from RBX treatment may be most prominent in patients with severe macular edema at baseline, and trials investigating this therapy may benefit from stratification according to baseline leakage. (Invest Opbthalmol Vis Sci. 2005;46:3855-3858) DOI:10.1167/iovs.05-0096

$\mathrm{D}$ iabetic macular edema is a major complication of diabetes mellitus, often leading to severe visual loss. The condition results from excessive vascular leakage from retinal capillaries and pathologic accumulation of extracellular fluid within the neurosensory retina. Although various treatment modalities are available, they are often best applied as preventive measures or

From the ${ }^{1}$ Department of Ophthalmology, Herlev Hospital, University of Copenhagen, Denmark; and the ${ }^{2}$ Harvard Medical School and ${ }^{3}$ Beetham Eye Institute, Joslin Diabetes Center, Boston, Massachusetts. Supported by Eli Lilly and Company and by Grant $8-2002-130$, a Patient-Oriented Diabetes Research Career Award from the Juvenile Diabetes Research Foundation.

Submitted for publication January 25, 2005; revised June 22, 2005; accepted August 22, 2005.

Disclosure: C. Strøm, Eli Lilly and Company (F); B. Sander, Eli Lilly and Company (F); K. Klemp, Eli Lilly and Company (F); L.P. Aiello, (C); H. Lund-Andersen, (C); M. Larsen, (C)

The publication costs of this article were defrayed in part by page charge payment. This article must therefore be marked "advertise$m e n t "$ in accordance with 18 U.S.C. $\$ 1734$ solely to indicate this fact.

Corresponding author: Michael Larsen, Department of Ophthalmology, Herlev Hospital, Herlev Ringvej 75, DK-2730 Herlev, Denmark; mla@dadlnet.dk. have little effect on already manifest visual loss. This is true of the classic current interventions, including optimization of glycemia control, control of arterial hypertension, and retinal photocoagulation treatment. ${ }^{1-4}$ Photocoagulation has the additional disadvantages of being a destructive procedure that does not usually restore already lost vision, although its use can reduce further visual loss. ${ }^{4}$ Consequently, there is an obvious clinical need for more effective and less destructive therapies for diabetic macular edema.

Vascular endothelial growth factor (VEGF) is upregulated in diabetic retinopathy and promotes leakage from retinal vessels. ${ }^{5,6}$ In animals, pharmacological inhibition of protein kinase C $\beta$ reduces intraocular VEGF- and diabetes-induced bloodretinal barrier leakage. ${ }^{5,6}$ In the present study, we examined the effect on blood-retinal barrier permeability in patients with diabetic macular edema who were treated with an orally administered PKC $\beta$ inhibitor, ruboxistaurin mesylate (RBX; LY333531). , $^{\text {, }}$

\section{Methods}

Seventy-four eyes of 54 patients with diabetic macular edema were enrolled in the study. Nine patients failed to complete the study: Three patients died (one of cardiovascular disease, two of cancer), five patients withdrew their consent for reasons unrelated to the study, and one patient suffered an adverse event (skin rash) and was discontinued. Five eyes in three patients were excluded because of potential interference with the measurement of blood-retinal barrier permeability due to posterior vitreous liquefaction. The vitreous was evaluated from 30-minute vitreous fluorometry scans, a horizontal vitreous concentration curve being considered evidence of vitreous degeneration. ${ }^{8-10}$ Photocoagulation treatment for fovea-threatening diabetic macular edema was given during the study in two eyes with vitreous degeneration and in two eyes of two other patients. All four eyes were excluded from analysis. Thus, 55 (74\%) eyes in $41(76 \%)$ patients were included in the data analysis (placebo: 13 eyes; $4 \mathrm{mg} / \mathrm{d}$ : 17 eyes; 16 $\mathrm{mg} / \mathrm{d}$ : 11 eyes; $32 \mathrm{mg} / \mathrm{d}$ : 14 eyes). At baseline, mean age was 51.9 (median, 54; range, 24-69) years; mean duration of diabetes in patients with type I diabetes, 22.9 (median, 20; range, 16-32) years; and mean duration in patients with type II diabetes 12.9 (median, 13; range, 2-26) years. The study population comprised 11 women and 30 men, of whom 12 had type I diabetes, and 29 had type II diabetes (Table 1).

The present study was designed as an exploratory substudy using vitreous fluorometry to elucidate the effect of RBX on blood-retinal barrier permeability, as part of a larger double-masked, placebo-controlled, dose-ranging, parallel, randomized, multicenter, multinational clinical trial. The study adhered to the tenets of the Declaration of Helsinki, and informed consent was obtained from all patients before they were enrolled in the study, which was conducted according to the ICH-Guidelines for Good Clinical Practice (ICH GCP). The main study was approved by the FDA and EMEA and locally by The Danish Medicines Agency and the medical ethics committee of Copenhagen County. The substudy was approved locally. 
TABLE 1. Best-Corrected ETDRS Visual Acuity and Blood-Retinal Barrier Permeability in Relation to Systemic RBX Treatment of Diabetic Macular Edema and Duration of Therapy

\begin{tabular}{|c|c|c|c|c|}
\hline $\begin{array}{c}\text { Ocular Characteristics of Eyes du } \\
\text { Systemic Treatment with RBX } \\
(n=42 \text { Eyes }) \text { or Placebo } \\
(n=13 \text { Eyes })\end{array}$ & Baseline & 3 Months & 12 Months & 18 Months \\
\hline Visual acuity, placebo (letters) & $87(85-90)$ & $87(83-91)$ & $88(85-91)$ & $87(84-90)$ \\
\hline Visual acuity, RBX (letters) & $87(85-89)$ & $88(86-89)$ & $87(85-89)$ & $88(86-90)$ \\
\hline Permeability, placebo (nm/s) & $4.29(2.6-6.4)$ & $4.30(2.5-6.6)$ & $2.99(1.4-5.1)$ & $4.06(2.3-6.4)$ \\
\hline Permeability, RBX (nm/s) & $4.44(3.3-5.7)$ & $4.49(3.3-5.8)$ & $3.60(2.8-4.5)$ & $4.14(3.1-5.3)$ \\
\hline
\end{tabular}

At baseline, no significant difference was found between placebo and ruboxistaurin for ETDRS visual acuity ( 85 letters $=20 / 20$ Snellen) or permeability (mean, 95\% CI). In healthy subjects blood-retinal barrier permeability is $2.0 \pm 0.48 \mathrm{~nm} / \mathrm{s}$ (mean \pm SD).

Ocular eligibility was defined as the presence of one sixth or more of disc area (DA) of definite retinal thickening within two disc diameters (DD) of the center of the macula and ETDRS severity of retinopathy level $\leq 47 \mathrm{~A}$, as determined by stereoscopic fundus photograph grading. ${ }^{11}$ Ocular ineligibility was defined as the presence of clinically significant macular edema, except that retinal thickening or hard exudates adjacent to retinal thickening at/or within $500 \mu \mathrm{m}$ but no closer than $300 \mu \mathrm{m}$ from the fovea was allowed if visual acuity was $\geq 77$ ETDRS letters. ${ }^{12}$ The patients were randomly assigned to one of four study arms (RBX 4, 16, or $32 \mathrm{mg} / \mathrm{d}$ or placebo) and examined at baseline and 3, 12, and 18 months. All patients were being observed closely and were monitored continuously for progression of macular edema and retinopathy.

The primary end point of the study was defined as a change in permeability of the blood-retinal barrier as determined by vitreous fluorometry. The method is an extension of fundus fluorescein angiography whereby retinal vascular leakage of fluorescein into the vitreous is quantitatively assessed by an optical instrument and used to calculate a summary measure of blood-retinal barrier permeability. In healthy subjects, the permeability is $2.0 \pm 0.48 \mathrm{~nm} / \mathrm{s}$ (mean $\pm \mathrm{SD}$ ).$^{13-17}$ Secondary end points included change in best corrected ETDRS visual acuity at $4 \mathrm{~m}, \mathrm{HbA}_{1 \mathrm{c}}$ level, and resting arterial blood pressure. The level of diabetic retinopathy was graded with seven standard field stereoscopic color fundus photographs evaluated by the Wisconsin Fundus Photographic Reading Center (University of Wisconsin, Madison, WI). The study included ETDRS grading levels 35, 43, 47, 53, and higher than 53. Deterioration of retinopathy was defined as an increase of one or more levels and improvement or stable retinopathy as a decrease or no change.

The effect of RBX treatment at any dosage was compared statistically with that of a placebo, incorporating data from repeated measurements at all visits and analyzed using a mixed linear model, including repeated measures and random effects. The latter accounts for random effects and interaction between patients and eyes, when more than one eye was included per patient, which happened in 14 patients. The dependent variable was blood-retinal barrier permeability. Independent variables included $\mathrm{HbA}_{1 \mathrm{c}}$, systolic and diastolic blood pressure, plasma lipids, retinopathy level, baseline blood-retinal barrier permeability, duration of treatment, and interactions between these variables and treatment. As independent variables, the final model included time, $\mathrm{HbA}_{1 \mathrm{c}}$ level, and baseline blood-retinal barrier permeability on the basis of the descriptive factors found to be of statistical significance after a successive removal of all interactions and main effects with $P>0.05$. Square-root transformation was applied to the permeabilities to obtain a regular distribution of residuals. A post hoc analysis was also performed comparing placebo and the three different RBX doses. The relation between baseline permeability and the level of retinopathy was tested with a generalized linear model. The effect of treatment on the change in retinopathy during the study was analyzed with the Fisher exact test (comparing improved and stable retinopathy versus increasing levels of retinopathy). Student's $t$-test was used for comparison of quantitative variables between the placebo- and the RBX-treated groups. The level of statistical significance was set at 5\%. Data were analyzed on computer (SAS software package, ver. 8e; SAS Institute, Cary, NC).

A post hoc evaluation of baseline stereo fundus photographs by the central Reading Center at University of Wisconsin stated that $62 \%$ of the 55 eyes were defined as non-clinically significant macular edema, and 38\% were CSME level 4 and 5 by a new macular edema grading scale with a total of 11 levels from questionable edema (level 1) to central involvement (level 11, Wisconsin DME Severity Scale; Davis R, personal communication, April 2005; recorded by Girach A, Sander B). Inclusion of data evaluated by this unpublished macular edema grading scale did not influence the conclusion of the study.

\section{Results}

After 18 months of RBX treatment for diabetic macular edema, retinal vascular leakage at baseline was a significant determinant of the outcome of RBX treatment (Table 1). The effect of RBX treatment compared with placebo was increased in proportion to baseline permeability, a reduction in retinal vascular leakage being statistically significant when baseline permeability was $5.8 \mathrm{~nm} / \mathrm{s}(P=0.032$; Table 2 , Fig. 1$)$ or higher. This value is nearly three times the permeability found in healthy subjects.

TABLE 2. Blood-Retinal Barrier Permeability in Relation to the Extent of Baseline Permeability, Systemic RBX Treatment of Diabetic Macular Edema and Duration of Therapy

\begin{tabular}{lcccc}
\hline Cut-off Baseline Permeability per Group & $\begin{array}{c}\text { Baseline } \\
\text { Permeability }\end{array}$ & $\begin{array}{c}\text { 3-Month } \\
\text { Permeability }\end{array}$ & $\begin{array}{c}\text { 12-Month } \\
\text { Permeability }\end{array}$ & $\begin{array}{c}\text { 18-Month } \\
\text { Permeability }\end{array}$ \\
\hline Low baseline permeability, placebo, $n=10$ & $3.00(2.3-3.7)$ & $3.17(2.4-4.0)$ & $1.79(1.2-2.5)$ & $2.73(1.9-3.7)$ \\
Low baseline permeability, RBX, $n=34$ & $3.10(2.7-3.6)$ & $3.42(2.6-4.3)$ & $2.82(2.4-3.3)$ & $3.15(2.5-3.8)$ \\
High baseline permeability, placebo, $n=3$ & $10.23(1.4-7.2)$ & $9.34(0.005-38.2)$ & $9.13(0.73-26.9)$ & $10.37(0.88-30.3)$ \\
High baseline permeability, RBX, $n=8$ & $12.74(6.7-20.7)$ & $10.65(5.1-18.1)$ & $7.95(3.4-14.5)$ & $9.83(4.6-17.0)$ \\
\hline
\end{tabular}

Interaction between treatment effect and baseline permeability is shown by post hoc stratification into low baseline permeability $(5.8 \mathrm{~nm} / \mathrm{s}$ or lower) and high baseline permeability (above $5.8 \mathrm{~nm} / \mathrm{s}$ ), RBX treatment being associated in the latter group with a reduction in blood-retinal barrier permeability during the trial, compared with placebo. Permeability is expressed as mean nanometers/second (95\% CI). 


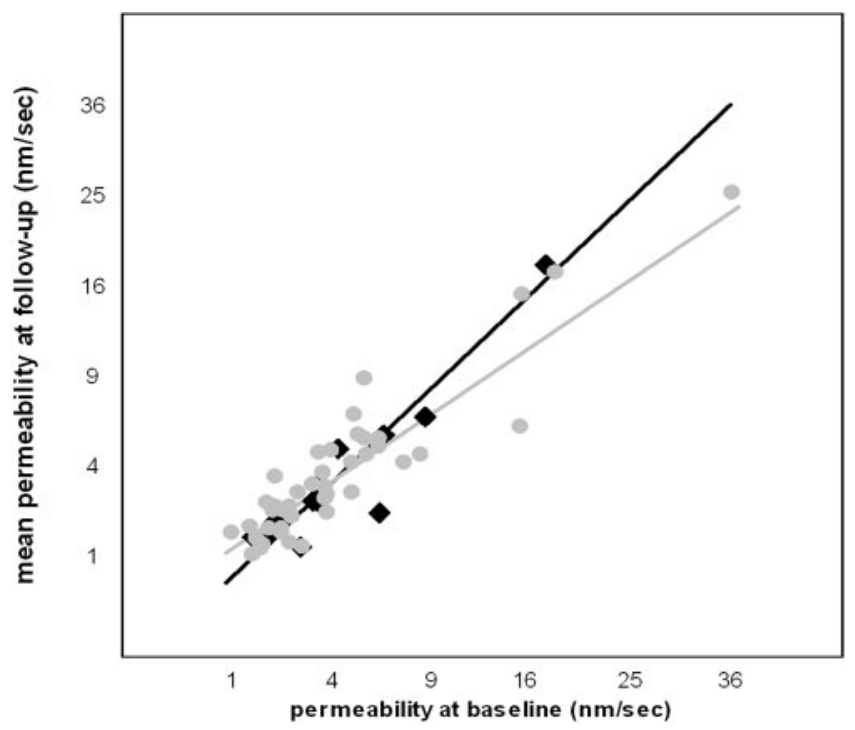

FigURE 1. Retinal vascular leakage during 18 months of RBX (circles) or placebo (diamonds) treatment (mean of three examinations per eye, at 3,12 , and 18 months) in relation to baseline retinal vascular leakage ( $x$-axis) in patients with diabetic macular edema. The relation between baseline and follow-up leakage, statistically modeled for RBX (gray line) and placebo (black line) in a mixed model, illustrates the interaction between baseline permeability and treatment. In eyes with baseline permeability of $5.8 \mathrm{~nm} / \mathrm{s}$ or higher-a nearly threefold increase compared with healthy subjects- $\mathrm{RBX}$ treatment was associated with a reduction in permeability during the trial relative to placebo $(P=0.032)$.

In both treatment and placebo groups, $\mathrm{HbA}_{1 \mathrm{c}}$ decreased during the study ( $P=0.0004$, Table 3 ). $\mathrm{HbA}_{1 \mathrm{c}}$ level was included in the statistical model; however, neither baseline $\mathrm{HbA}_{1 \mathrm{c}}$ nor change in $\mathrm{HbA}_{1 \mathrm{c}}$ during the study differed between the placebo and RBX treatment groups $(P>0.43)$. Systolic and diastolic blood pressure did not change significantly during the study and were not included in the model (Table 3).

Even if the number of eyes in the different dose arms was too small to draw firm conclusions, the results were the following: For baseline permeability higher than $5.8 \mathrm{~nm} / \mathrm{s}$, the effect of treatment in relation to placebo was significant $(P<$ 0.05 ) for $4 \mathrm{mg} / \mathrm{d}$ but not for 16 or $32 \mathrm{mg} / \mathrm{d}$. The analysis also demonstrated a nonlinear trend in treatment response, in that the effect for high baseline permeability was most pronounced for $32 \mathrm{mg} / \mathrm{d}$, lower for $4 \mathrm{mg} / \mathrm{d}$, and lowest for $16 \mathrm{mg} / \mathrm{d}$, suggesting that the number of eyes per subgroup is too low to permit reliable evaluation of the dose-response relationship.

The severity of retinopathy did not exert an independent effect on treatment outcome in this study $(P=0.091$ in the initial model). Baseline permeability was, however, correlated to baseline retinopathy level ( $P=0.040$, analysis of variance). No significant progression in ETDRS retinopathy level was found during the study $(P=0.21)$.

\section{Discussion}

The present study in diabetic patients with macular edema at baseline was designed to explore the effect on the bloodretinal barrier permeability of RBX, a novel orally administered protein kinase $\mathrm{C} \beta$ inhibitor that is hypothesized to reduce proliferative retinopathy and retinal vascular leakage in experimental diabetes. ${ }^{6,18,19}$ Based on the assumption that stabilization of the blood-retinal barrier is essential for arresting the progression of diabetic macular edema, our primary objective was to compare blood-retinal barrier permeability in patients treated with RBX with that in patients who did not receive RBX during the 18-month study.

Using an empiric statistical model comprising baseline bloodretinal barrier permeability as a descriptive variable, we found a significant association between blood-retinal barrier permeability and treatment effect. A treatment-related decrease in permeability was observed, but this was only statistically significant when baseline permeability was greater than $5.8 \mathrm{~nm} / \mathrm{s}$, above which the mean reduction in permeability was $30 \%$ (from 12.74 to $9.83 \mathrm{~nm} / \mathrm{s}$, Table 2). This effect was found even though baseline $\mathrm{HbA}_{1 \mathrm{c}}$ and baseline permeability tended to be higher in the RBX group than in placebo. This finding has potential implication in the design of clinical studies of PKC and/or VEGF inhibitors for the treatment of diabetic macular edema, because it suggests that treatment benefit is most prominent in more advanced disease. In a study comparing clinically significant diabetic macular edema (CSME) with diabetic macular edema below this level of severity, eyes with CSME demonstrated a mean permeability of $11.3 \mathrm{~nm} / \mathrm{s}$ and non-CSME eyes a mean permeability of CSME $3.6 \mathrm{~nm} / \mathrm{s}^{9}$

More severe levels of retinopathy and retinal edema are associated with increased blood-retinal barrier permeability $^{9,20}$ and higher concentrations of VEGF in the retina and vitreous. ${ }^{6}$ These effects are thought to be mediated, at least in part, by increased PKC $\beta$ activity. ${ }^{6}$ Because RBX is a selective inhibitor of protein kinase $\mathrm{C} \beta$, an increased therapeutic benefit of RBX with increasing blood-retinal barrier permeability might be expected.

Using vitreous fluorometry, we have previously documented the effect of antihypertensive treatment ${ }^{21}$ on lowering blood-retinal barrier permeability, a finding later determined to be in agreement with the results of the UKPDS (U.K. Prospective Diabetes Study). ${ }^{2}$ Thus, the leakage measurement method used in the present study seems to be valuable for assessment of blood-retinal barrier permeability as an expres-

TABLE 3. $\mathrm{HbA}_{1 \mathrm{c}}$ and Arterial Blood Pressure in Relation to Systemic RBX Treatment of Diabetic Macular Edema and Duration of Therapy

\begin{tabular}{|c|c|c|c|c|}
\hline $\begin{array}{c}\text { Systemic Characteristics of Eyes duri } \\
\text { Treatment with RBX }(n=30) \text { or } \\
\text { Placebo }(n=11)\end{array}$ & Baseline & 3 Months & 12 Months & 18 Months \\
\hline $\mathrm{HbA}_{1 \mathrm{c}}$, placebo (\%) & $8.82(8.2-9.4)$ & $8.67(7.9-9.5)$ & $8.64(8.1-9.2)$ & $8.51(7.7-9.3)$ \\
\hline $\mathrm{HbA}_{1 \mathrm{c}}, \mathrm{RBX}(\%)$ & $9.25(8.8-9.7)$ & $9.02(8.6-9.4)$ & $9.07(8.7-9.5)$ & $8.79(8.3-9.2)$ \\
\hline Diastolic BP, placebo $(\mathrm{mm} \mathrm{Hg})$ & $79(73-85)$ & $77(71-84)$ & $77(74-81)$ & $76(71-81)$ \\
\hline Diastolic BP, RBX (mm Hg) & $83(79-87)$ & $80(76-83)$ & $80(77-82)$ & $78(75-80)$ \\
\hline Systolic BP, placebo $(\mathrm{mm} \mathrm{Hg})$ & $132(120-143)$ & $136(123-143)$ & $129(117-140)$ & $131(120-143)$ \\
\hline Systolic BP, $(\mathrm{mm} \mathrm{Hg})$ & $138(133-144)$ & $132(126-138)$ & $138(134-143)$ & $137(132-142)$ \\
\hline
\end{tabular}

At baseline, no significant difference was found between the placebo and $\mathrm{RBX}$ groups in $\mathrm{HbA}_{1 \mathrm{c}}$ or blood pressure. The level of $\mathrm{HbA}$ decreased during the study in all groups $(P=0.0004)$. Blood pressure did not change significantly during the study. Data are expressed as the mean $(95 \% \mathrm{CI})$. 
sion of the effect of diabetes on the retina, although limitations exist regarding the distinction between vascular leakage from the retina into the vitreous and vascular leakage that is confined within the retina and causes edema.

In summary, selective inhibition of protein kinase $\mathrm{C} \beta$ using orally administered RBX in patients with diabetic macular edema was associated with reduction of retinal vascular leakage in eyes with greater baseline leakage, becoming statistically significant when marked permeability was present at baseline. These data suggest that clinical benefit from RBX treatment may be most prominent in patients with severe macular edema at baseline, and trials investigating this therapy may benefit from stratification according to baseline retinal vascular leakage or emphasis on this patient subgroup.

\section{References}

1. The Diabetes Control and Complications Trial Research Group The effect of intensive treatment of diabetes on the development and progression of long-term complications in insulin-dependent diabetes mellitus. $N$ Engl J Med. 1993;329:977-986.

2. UK Prospective Diabetes Study Group. Tight blood pressure control and risk of macrovascular and microvascular complications in type 2 diabetes: UKPDS 38. BMJ. 1998;317:703-713.

3. Writing Team for the Diabetes Control and Complications Trial/ Epidemiology of Diabetes Interventions and Complications Research Group. Effect of intensive therapy on the microvascular complications of type 1 diabetes mellitus. JAMA. 2002;287:25632569.

4. Early Treatment Diabetic Retinopathy Study Research Group. Photocoagulation for diabetic macular edema. Early treatment diabetic retinopathy study report number 1 . Arch Ophthalmol 1985;103: 1796-1806.

5. Aiello LP: The potential role of PKC beta in diabetic retinopathy ad macular edema. Surv Opbthalmol. 2002;47(suppl 2):S263-S269.

6. Aiello LP, Bursell SE, Clermont A, et al. Vascular endothelial growth factor-induced retinal permeability is mediated by protein kinase $\mathrm{C}$ in vivo and suppressed by an orally effective beta-isoformselective inhibitor. Diabetes. 1997;46:1473-1480.

7. Ways DK, Sheetz MJ. The role of protein kinase C in the development of the complications of diabetes. Vitam Horm. 2000;60: 149-193.

8. Sander B, Larsen M, Moldow B, Lund-Andersen H. Diabetic macular edema: passive and active transport of fluorescein through the blood-retina barrier. Invest Ophthalmol Vis Sci. 2001;42:433-438.
9. Sander B, Larsen M, Engler C, et al. Diabetic macular oedema: a comparison of vitreous fluorometry, angiography, and retinopathy. Br J Opbthalmol. 2002;86:316-320.

10. Moldow B, Sander B, Larsen M, Lu, Lund-Andersen H. Effects of acetazolamide on passive and active transport of fluorescein across the normal BRB. Invest Opbthalmol Vis Sci. 1999;40:1770-1775.

11. Early Treatment Diabetic Retinopathy Study Research Group. Grading diabetic retinopathy from stereoscopic color fundus photographs: an extension of the modified Airlie House classification-ETDRS report number 10. Opbthalmology 1991;98(suppl 5):786-806.

12. Klein R, Klein BE, Moss SE, Davis MD, DeMets DL. The Wisconsin epidemiologic study of diabetic retinopathy. IV. Diabetic macular edema. Ophthalmology. 1984;91:1464-1474.

13. Dalgaard P, Larsen M. Fitting numerical solutions of differential equations to experimental data: a case study and some general remarks. Biometrics. 1990;46:1097-1109.

14. Larsen M, Lund-Andersen H. Lens fluorometry: light-attenuation effects and estimation of total lens transmittance. Graefes Arch Clin Exp Opbthalmol. 1991;229:363-370.

15. Larsen M, Dalgaard $P$, Lund-Andersen $H$. Differential spectrofluorometry in the human vitreous: blood-retina barrier permeability to fluorescein and fluorescein glucuronide. Graefes Arch Clin Exp Ophthalmol. 1991;229:350-357.

16. Larsen M, Dalgaard P, Lund-Andersen H. Determination of spatial coordinates in ocular fluorometry. Graefes Arch Clin Exp Ophthalmol. 1991;229:358-362.

17. Lund-Andersen H, Krogsaa B, la Cour M, Larsen J. Quantitative vitreous fluorophotometry applying a mathematical model of the eye. Invest Ophthalmol Vis Sci. 1985;26:698-710.

18. Danis RP, Bingaman DP, Jirousek M, Yang Y. Inhibition of intraocular neovascularization caused by retinal ischemia in pigs by PKC beta inhibition with LY333531. Invest Opbthalmol Vis Sci. 1998; 39:171-179.

19. Jirousek MR, Koya D, Takagi C, et al. Amelioration of vascular dysfunctions in diabetic rats by an oral PKC beta inhibitor. Science. 1996;272:728-731.

20. Krogsaa B, Lund-Andersen H, Mehlsen J, Sestoft L, Larsen J. The blood-retinal barrier permeability in diabetic patients. Acta $O p b$ thalmol (Copenb). 1981;59:689-694.

21. Larsen M, Hommel E, Parving H-H, Lund-Andersen H. Protective effect of captopril on the blood-retina barrier in normotensive insulin-dependent diabetic patients with nephropathy and background retinopathy. Graefes Arch Clin Exp Ophthalmol. 1990; 228:505-509. 